\title{
Very strong chalcogen bonding: Is oxygen in molecules capable of forming it? A First-Principles Perspective
}

\author{
Pradeep Varadwaj ${ }^{1}$, Arpita Varadwaj ${ }^{2}$, and Helder Marques ${ }^{3}$ \\ ${ }^{1}$ The University of Tokyo \\ ${ }^{2}$ National Institute of Advanced Industrial Science and Technology Tsukuba Center \\ Tsukuba Central \\ ${ }^{3}$ University of the Witwatersrand
}

June 18, 2020

\begin{abstract}
There are views prevalent in the noncovalent chemistry literature that i) the $O$ atom in molecules cannot form a chalcogen bond, and ii) if formed, this bond is very weak. We have shown here that these views are not necessarily true since the attractive energy between the oxygen atom of some molecules and several electron-rich anionic bases examined in a series of 34 ion-molecule complexes varied from the weak (ca $-2.30 \mathrm{kcal}$ mol-1) to the ultra-strong ( $-90.10 \mathrm{kcal}$ mol-1). The [MP2 /aug-ccpVTZ] binding energies for several of these complexes were found to be comparable to or significantly larger than that of the well-known hydrogen bond complex $[\mathrm{FH} \cdots \mathrm{F}]-(\sim 40 \mathrm{kcal} \mathrm{mol}-1)$. The nature of the intermolecular interactions was examined using the quantum theory of atoms in molecules, second-order natural bond orbital and symmetric adaptive perturbation theory energy decomposition analyses. It was found that many of these interactions comprise mixed bonding character (ionic and covalent), especially manifest in the moderate to strongly bound complexes. All these can be explained by an n (lone-pair bonding orbital) $->\sigma^{*}$ (anti-bonding orbital) donor-acceptor charge transfer delocalization. This study, therefore, demonstrates that the covalently bound oxygen atom in molecules can have a significant ability to act as an unusually strong chalcogen bond donor.
\end{abstract}




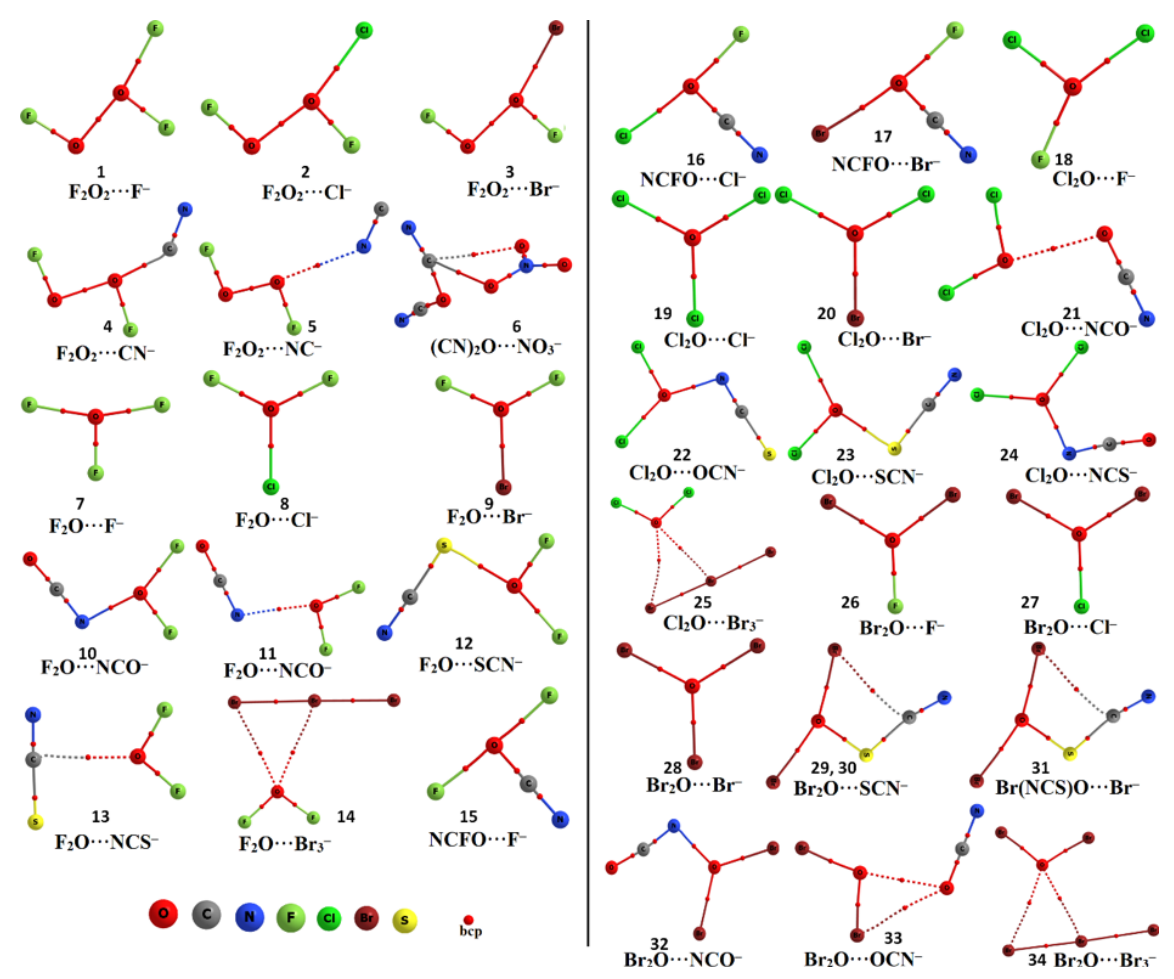

\section{Hosted file}

MS_s.pdf available at https://authorea.com/users/334543/articles/460514-very-strongchalcogen-bonding-is-oxygen-in-molecules-capable-of-forming-it-a-first-principlesperspective

\section{Hosted file}

Supplementary_Information.docx available at https://authorea.com/users/334543/articles/ 460514-very-strong-chalcogen-bonding-is-oxygen-in-molecules-capable-of-forming-it-afirst-principles-perspective 